\title{
Regenerating Historic Urban Areas Through Sustainable Livelihoods - Problematizing Economy Within Historic Urban Areas
}

\author{
NIYATI JIGYASU \\ Professor, Chitkara School of Planning and Architecture, Chitkara University Punjab, \\ India
}

\section{Email: niyati.jigyasu@chitkara.edu.in}

Received: November 09, 2015|Revised: February 02, 2016|Accepted: March 06, 2016

Published online: July 04,2016

The Author(s) 2016. This article is published with open access at www.chitkara.edu.in/publications

\begin{abstract}
In the historic core of Ahmedabad, the Archaeological Survey of India (ASI) reported major encroachments, leading to destruction of the tomb of Darya Khan [5]. The encroachments were undertaken by the local community for residential purposes and by the informal sector for commercial purpose, for which the local administration as well as the community were blamed. Urban conservation, as the example indicates, is not limited to the preservation of buildings. It considers architecture of the built heritage as one of the elements of the overall urban setting that includes living expressions such as oral traditions, performing arts, social practices, rituals, festivals, and traditional skills implicitly embedded in the community. Heritage is, thus not only a legacy to be preserved for future generations, but also something for and abou,t the existing communities.

This paper is based on the premise that today, the sustainability of historic areas rests on due consideration being given to the role of the communities and improvement of their quality of life through economic augmentation. There is a major shift in focus on the economic value of cultural heritage. But, merely considering the economic value of a historic site and its revenue options will not lead to a comprehensive solution for urban conservation. The aim of this paper is to understand the significance of traditional economy in historic urban areas, the current processes of transformation in this sector, and also its potential contribution for managing urban heritage and aiming towards larger goal of sustainability.
\end{abstract}

Keywords: Sustainability, Urban conservation, Cultural capital, Traditional crafts

\section{INTRODUCTION}

Creative Space (CS)

Vol-4, No-1

July 2016

The historic urban areas are home to a wealth of tangible and intangible cultural assets that gives them a distinct identity and sets them apart from others. The urban heritage within them is representative of layers of social, cultural and economic assets and resources that have been created,

CHIKARA 司

(C) 2014 by Chitkara

University. All Rights

Reserved. 


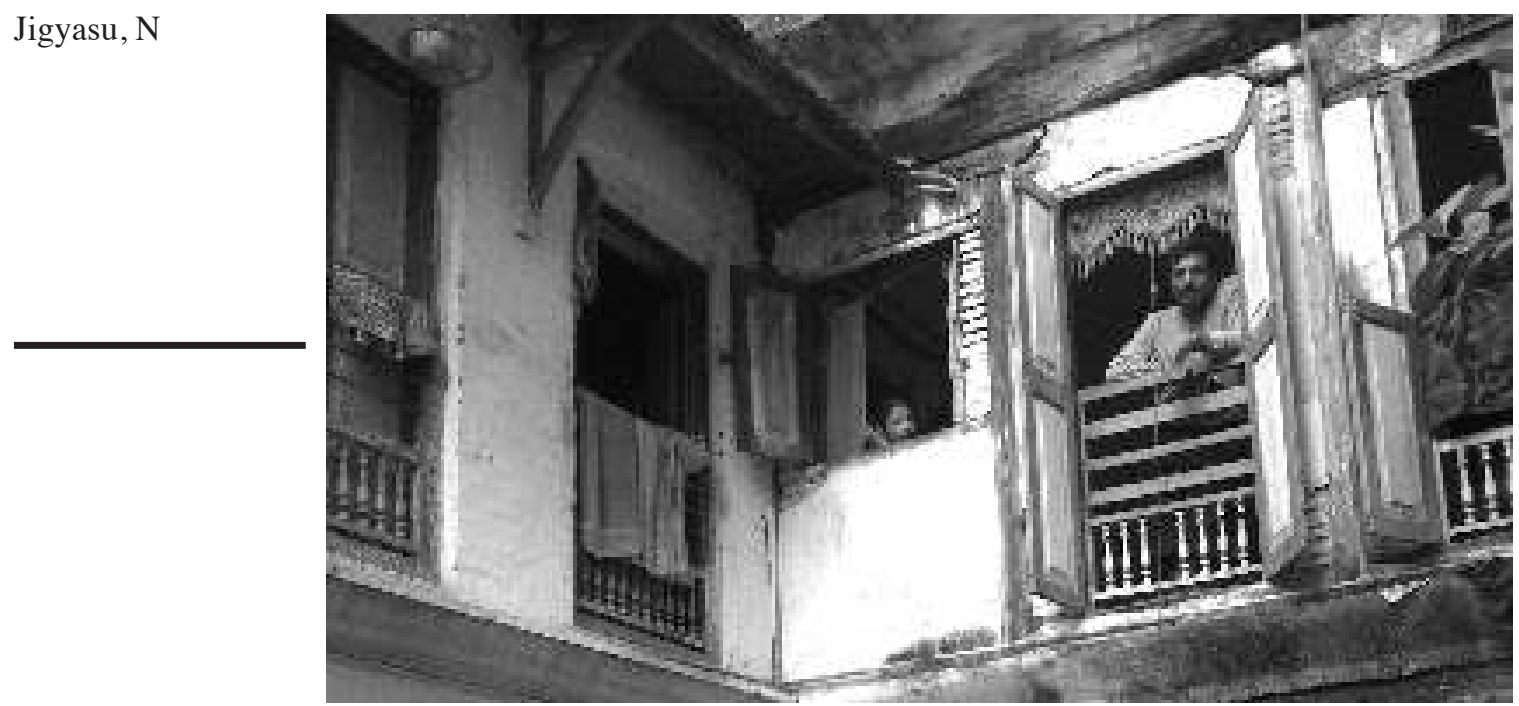

Figure 1: Sustainability of Community - a major concern in HUA.

interpreted and handed down by successive generations [13]. It is for this very reason that people are considered as the major stakeholders whose existence becomes very much dependent on their adaptation to the changes over the time. It is increasingly believed that the sustainability and survival of historic areas will only be possible if these can play a prominent role in improving the quality of life of people, including augmentation of their economic status (Fig. 1).

Heritage is thus not only a legacy to be preserved for future generations, but also something for and about the existing communities. Heritage conservation has always sought to protect cultural, aesthetic, educational, environmental, social and historic values. It is only of recent, that 'economic value' has been added to this list. In the past, discussion on the economic component was considered by heritage professionals as demeaning to the importance of heritage values and was thus kept out of the debate. But recently, experts and doctrines in the field of heritage conservation are getting more focused on considering urban heritage as a strong economic driver and, therefore, striving towards harnessing its potential for economic progress in historic areas. The World Bank, which also funds culture-based projects, also refers to cultural heritage as an asset in all its tangible and intangible forms. In the last 20 years, the Inter-American Development Bank (IDB) has funded US\$ 670 million as loans for projects involving conservation and development projects in cultural heritage in Latin America [13]. With the UNESCO advocating the paradigm 


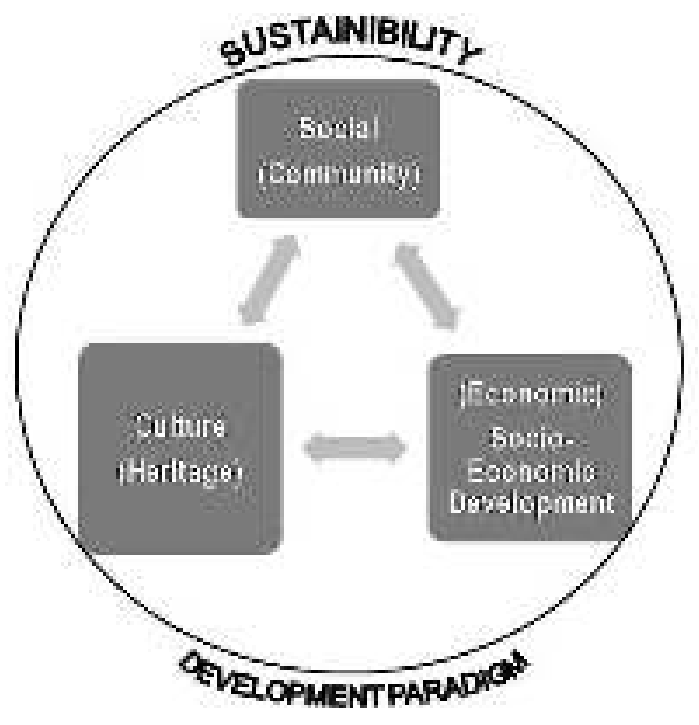

Regenerating Historic Urban Areas Through

Sustainable

Livelihoods -

Problematizing

Economy Within

Historic Urban

Areas

Figure 2: Connecting socioeconomic development of Community to Heritage.

of the historic urban landscape, due recognition is given to the economic dimension of the tangible and intangible values of urban heritage.

Today, though there is an initiation of focus on economics in historic urban areas, urban conservation has largely failed to address the drivers of local economy in historic districts. Most of the initiatives are limited to employment and revenue generation through tourism, which is primarily measured in terms of the number of tourists and used to justify investments in the conservation of monuments, sites, museums and heritage festivals. Even though tourism is an important source for high employment generation possibilities, the cultural dimension of development requires recognition that far exceeds the tourism sector [16]. There is a vital need to bring into consideration the traditional economy associated with the community in these areas. This is also the subject of discussion of the concept of 'creative economy', theory of 'creative cities' and, also of discussions by various heritage-related organizations.

It must be noted that the intangible culture forms the background of tangible cultural property, including monuments and sites and, that sustainable development needs to consider both aspects. The aim of this paper is to understand the significance of traditional economy in historic urban areas, the current processes of transformation in this sector and, also its potential contribution for protecting and managing urban heritage and moving towards larger goal of sustainable development (Fig. 2). 


\section{DEFINING URBAN HISTORIC AREAS AND URBAN HERITAGE}

The scope of "Urban Heritage" was earlier considered limited to monuments or their remains, or at best, sites or complexes containing a number of historic buildings. However, from the time of the declaration of World Heritage Convention in 1972 till today, the field of heritage conservation has undergone many amendments. From individual monuments to cultural landscapes, accommodating intangible values and aspects of everyday life, the scope of heritage has expanded considerably and subsequently conservation measures are needed to protect them for the future generation.

The Charter for Conservation of Historic Towns and Urban areas states that urban historic areas, large and small, include cities, towns and historic centres or quarters, together with their natural and man-made environments [5]. Beyond their role as historical documents, these areas embody the values of traditional urban cultures. In the Indian context, a definition put forward by Prof. A G K Menon states that: "Many historic cities do not contain individual buildings of exemplary merit, but as a precinct they represent a way of life and living which is an intangible characteristic of urban heritage". This definition clearly emphasizes the living dimensions of urban heritage in the Indian context.

UNESCO's recently adopted concept of 'Historic Urban Landscapes' advocates the intangible and tangible components of urban heritage in their territorial context as the key resources that contribute towards enhancing the liveability of urban areas and fostering economic development as well as social cohesion. HUL strives for integrating the goals of heritage protection with social and economic development of the associated community [2].

Today, most of the historic areas are located in a fragile environment, always straddling between ideologies of preservation and continuation. These areas are a mix of grand monuments and urban infill projects that either respect the historic context or overlook it completely. A position of laissez-faire policy leads to historic centres being left to run into slow disrepair and, are ultimately discarded by residents who start moving to areas outside this zone. In such scenarios, buildings with no significant heritage value either become rental properties or, are occupied by people with very low income. Another approach of elitist revitalization turns historic districts into "museums", where the past is merely seen in terms of the visual aspects of the historic built fabric. This could lead to a rise in property prices and predominance of offices and hotels - leading to loss of identitarian social capital [15].

In India especially, the priorities and mechanisms of governance are driven by different political, economic and social dynamics. Adding to this are the layers of complex local, informal governance that often conflicts with the bureaucratic rigid top-down approach of the formal government systems, 
Figure 3: Diagram showing the demarcation of economies linked to a heritage asset (Source: Asia-Europe Network of Urban Heritage For Sustainable Creative Economies).

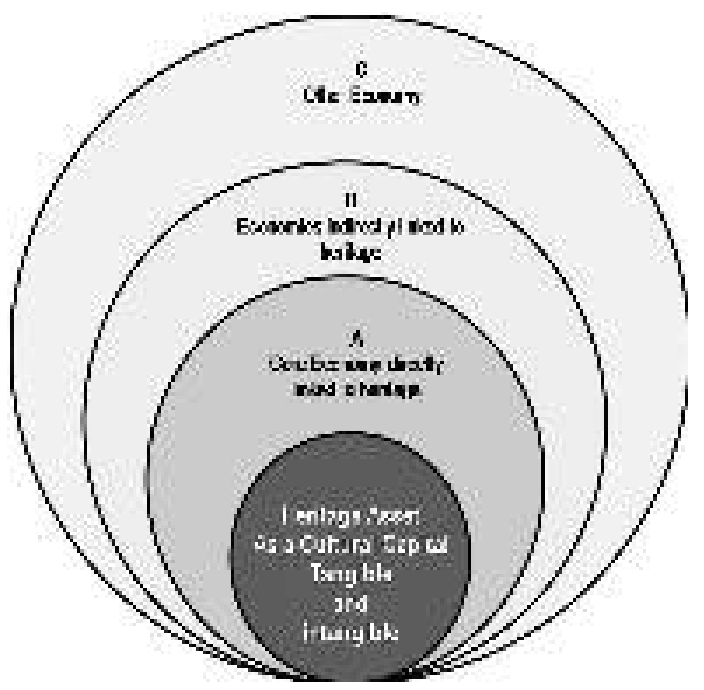

Regenerating Historic Urban Areas Through Sustainable Livelihoods Problematizing Economy Within Historic Urban Areas 53

leading to limited scope for community considerations whatsoever [9]. These concerns become more critical in historic urban areas for sites that do not have any legal protection and, hence, no legislation to keep a check on the processes of transformation. Listed below are some of the other common issues:

- Despite growing awareness of the importance of a wider approach to conservation beyond monuments, inadequate regulatory mechanisms, institutional arrangements, and human resources reinforce a traditional monument-centric approach.

- A lack of sound public policies, schemes, incentives and capacity for the effective management of cultural landscapes in the 21 st century persists.

- Historic areas are isolated from the wider economic development and physical transformation, creating pockets of poverty [1].

\section{CULTURAL HERITAGE AND ECONOMICS}

Cities are the engines of growth in most economies in both industrialized and developing countries and account for over 80 percent of global GDP. Hence, addressing the economy of the city is paramount for its future development. When the discussion is on the historic cities and areas, the economy includes a fair share of traditional livelihood options, many of which would be directly or indirectly linked to cultural heritage (Fig. 3). The benefits of cultural heritage on liveability and, its contribution to local economic development, has been considered in various studies and debates. Donovan Rypkema advocates 


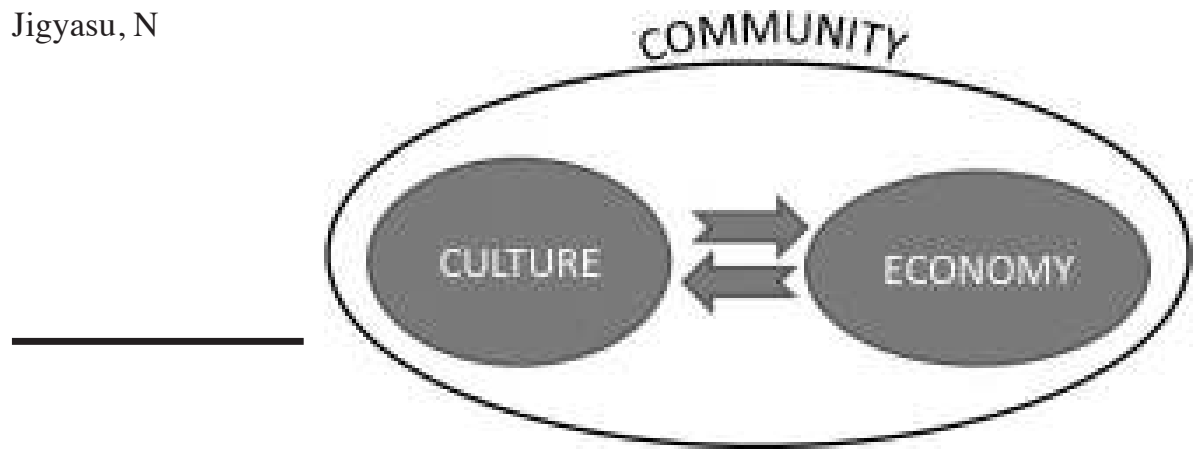

Figure 4: Culture can create economy and economy can sustain culture, if taken within the community agenda.

its relevance on jobs and livelihoods, along with other factors, in his work on economic impacts of cultural heritage. Tourism and its related service industries generate economic opportunities and increasing revenue through the tangible heritage of monuments. Livelihoods based on local knowledge, skills, labour, materials, and technologies have also generated economic growth to a limited extent. An environment soaked in culture nurtures creativity rooted in local knowledge and materials and is responsive to local geography, climate, and natural resources [3].

Hence, the understanding of the role of cultural heritage in generating employment and sustainable economic development is very important. This needs to be further incorporated into future urban planning and development policies [8]. Many urban conservation and development programmes fail in absence of due consideration to the cultural settings [7, 3]. "Millennium Goals 2015" propagates that Culture also enables development. Culture can be a means for promoting and sustaining economic progress and, it allows people to take onus for their development processes. David Throsby goes a step further by interpreting cultural heritage in terms of cultural capital. Similar to natural capital, cultural capital is also a wealth inherited from the past that can deteriorate over time, requires maintenance and compels the present generation to care for the assets so they can be handed down to future generations [12].

When culture is considered in terms of economy, creativity and culture become the drivers of development. This can help in quality of life and giving a more sustainable existence in a long term. This also gives recognition to the fact that what we refer to as "economy" is bound by the processes of social and cultural relations (Fig. 4). Economy itself is a part of culture, with cultural heritage being an influential asset for inclusive economic development. Cultural heritage can attract investment and offer opportunities for locally-based decent jobs to all groups within a society, including women 
and minority groups. These jobs, mainly relying on human and other localized resources, cannot be moved out of the community setup. The goods based on culture are idiosyncratic, requiring tacit knowledge for their creation, technical production, distribution. Investing in the cultural and creative sectors can be helpful for regenerating local based economy in areas that are affluent in cultural heritage and the creative industries [10]. As we look at capitalism at global level, the geographical specificity and idiosyncrasy of the cultural economy of urban areas become even more manifested.

Over the years, we have several examples of urban conservation in India. The Ahmedabad Walled City Area Project, undertaken jointly by the Ahmedabad Municipal Corporation (AMC) and Conservation and Research of Traditional Urban Architecture (CRUTA), is heavily inclined towards infrastructure development and building conservation. The project at Pondicherry by Asia Urbs, on the other hand, aimed at economic and environmental goals. As understood, economic improvement was mainly restricted to job generation for tourist-related activities such as heritage hotels, and informal sector jobs such as bike rentals, tour guides and tourism publication [4]. Though infrastructure and tourism development are very vital for urban conservation and do add to the quality of life of the community, economic sustainability through their inherited skills would not only make it more sustainable but also help in conservation of the intangible part of our urban heritage.

Supporting the traditional systems of knowledge transfer and integrating it into the formal and non-formal industry can bring the intangible cultural heritage into the forefront. At the same time, it would help in strengthening the economic base of the historic parts of the city by providing employment opportunities to the local inhabitants. However, the predominant top-down approach ends up supporting commercial operations that drive out the economically weaker section of the local population, thereby disturbing the social system of traditional neighbourhoods. Hence it is critical to create synergy between socio-economic growth and conservation strategies for sustainable solutions. [16].

\section{DEFINING TRADITIONAL ECONOMY IN HISTORIC URBAN AREAS}

Amartya Sen in his book, 'Freedom and Development', talks about "paying attention to the expansion of the "capabilities" of persons to lead the kind of lives they value - and have reason to value". This is mainly because, he goes on to add, "Income deprivations and capability deprivations often have considerable correlation linkages, it is important to avoid being mesmerized
Regenerating Historic Urban

Areas Through

Sustainable

Livelihoods -

Problematizing

Economy Within

Historic Urban

Areas 
into thinking that taking note of the former would somehow tell us enough about the latter. The connections are not that tight, and the departures are often much more important from a policy point of view than the limited concurrence of the two sets of variables"

With reference to historic areas, the inherent capabilities of the community lies in the intangible heritage, including traditions and living expressions inherited from our ancestors and passed on to our descendants. UNESCO, in its report on creative economy, talks about preservation and presentation of the same heritage assets as marketable assets. At the institutional level, economy is basically divided as primary (agriculture), secondary (industry) and tertiary (services). But, taking into consideration the historic urban areas, these classifications are not deemed fit. Hence, taking from some understanding of the various typologies of traditional economic systems that seem to exist in urban areas, this paper makes an attempt to make a broad classification based on the predominant attributes that contribute towards the local economy, e.g., religious attribute in the case of historic areas of Amritsar, or craft-based attribute in the case of town of Chanderi (Fig. 5).

This implies that the local economy of a urban historic area would be divided into traditional and contemporary, depending on the processes of achieving it. Thus traditional economy, described as traditional cultural expression, would include processes such as oral traditions, performing arts, social practices, rituals, festive events and, skills to produce traditional crafts of the communities who maintain, practice and develop them. Contemporary economy would include activities such as tourism related services and other modern day occupations, some of which would be linked to the heritage factor. Each of these classifications can be further divided into the tangible and the intangible. For ensuring sustainability of historic urban areas, both these economic dimensions should contribute towards the well-being of the local community.

Just as natural capital includes natural resources, ecosystems and biodiversity, so also does cultural capital contain cultural resources, cultural networks and cultural diversity embedded in the community [12]. Though challenges do vary with each city / historic urban areas, the most common concern is the impact of traditional economy and the involvement of the local community. Even in places where tourism is the major source of economy, it has sometimes been found that at times, in the name of tourism economic development of the local people at times get restricted to selling trinkets, artifacts, T-shirts, etc., which -- all too often -- are not even made locally nor are part of the traditional crafts / expressions. Such a disconnect affects the community adversely and, subsequently, the decline of intangible heritage [11]. 


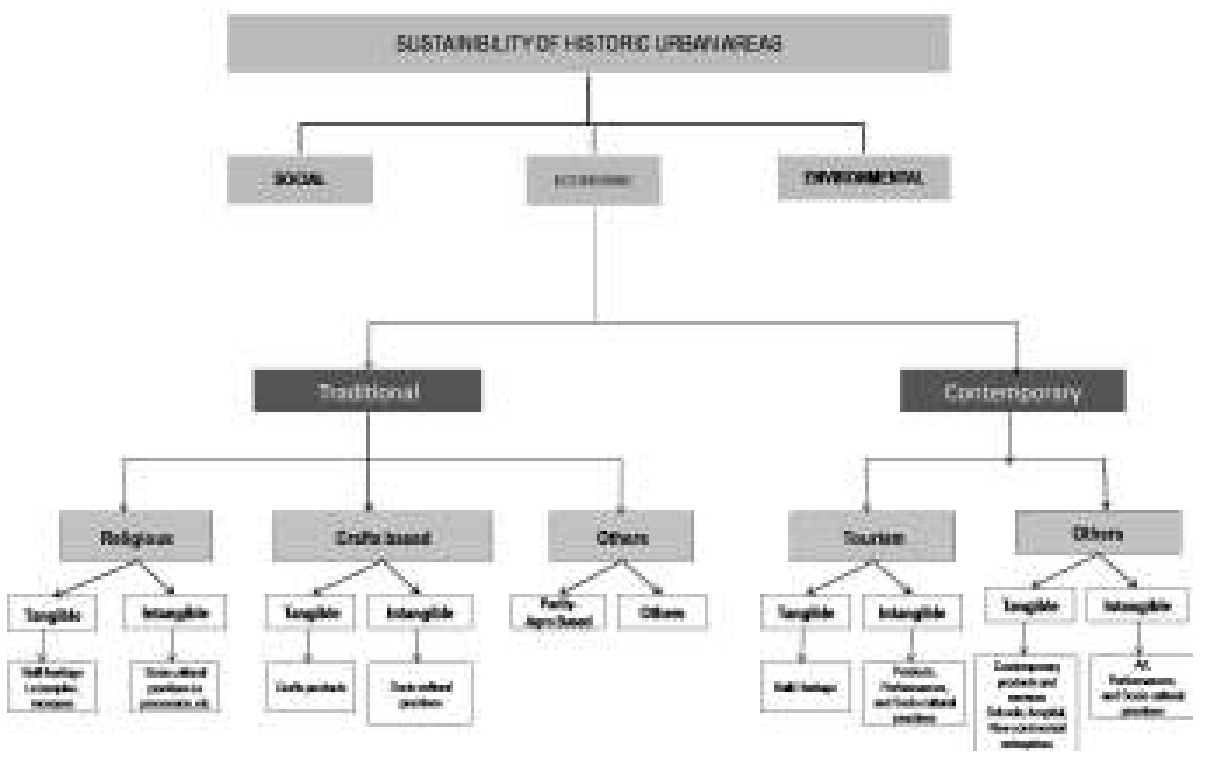

Regenerating Historic Urban Areas Through

Sustainable Livelihoods Problematizing Economy Within Historic Urban Areas

Figure 5: Economic Classification in HUA.

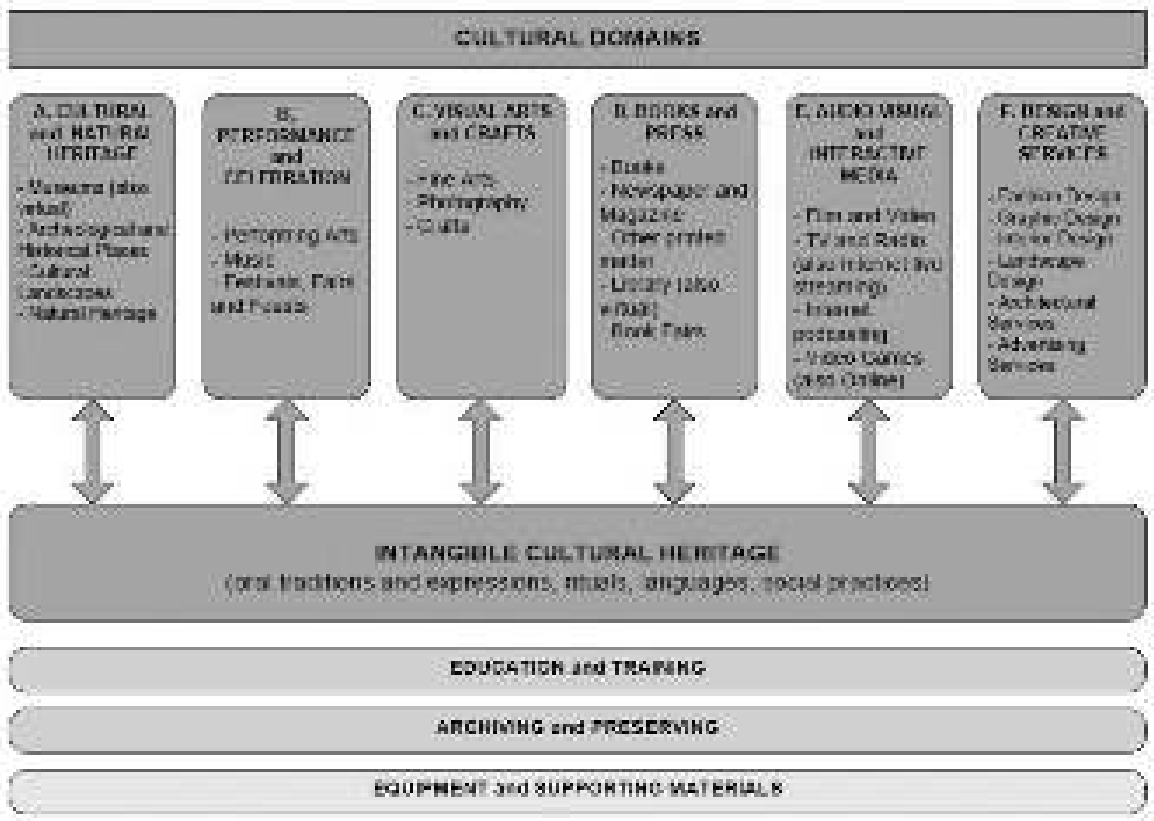

Figure 6: The 2009 UNESCO framework for cultural statistics (Source: UNESCO publication). 
Jigyasu, $\mathrm{N}$

\section{TRADITIONAL CRAFTS AS AN ECONOMIC DRIVER}

The need to consider traditional crafts as an economic driver has been advocated by various doctrines. UNESCO, in its report on creative economy, propagates the importance of creativity as an economic diver, traditional crafts being one of its sub-sets. The term "creative economy" was made more popular in 2001 by the British writer and media manager, John Hawkins. As a term it includes a wide range of fields, such as music, art, writing, fashion and design, and media industries, e.g., radio, publishing, film and television production. Since a great deal of cultural production, especially in developing countries is craftsbased, its scope goes beyond the technology-intensive production (Fig. 6).

UN reports have established that there is a sizable and strong economic sector based upon creative activities and, that it is a rapidly growing sector in world economy and provides feasible development options. Tradition, culture, arts and commerce make up a strong intertwined ecosystem in most Indian historic core. Strongly supported by beliefs, skills and aspirations, these lead to creation, production, transaction and fulfilment. In India, the perspective has been to emphasise on the intangible and the cultural aspects of urban heritage. But, it is the economic valuation that is missing. The need for evaluating its economic components stems from the very same reason that the cultural attributes too need to be quantified in terms of the economic and employment benefits.

The creative economy, inclusive of traditional crafts, differs from other sectors in many ways. The crafts sector is more compatible with micro enterprises, especially in developing countries. Many culture-based activities are primarily made up of small businesses or family businesses that are suited for locally-based development. A study in Baroda showed that making kites and kite thread are businesses passed on from generation to generation (Fig. 7). Also, such seasonal businesses provide revenue for the family for the entire year. Considering that majority of economy in India is based on local, informal businesses and the heritage of artisanal skills, creative economy is not a matter of choice in India. It is also critical that the scale of informality, both in terms of enterprise and employment or occupations, is very significant in India. The informal economy has been estimated to occupy as much as half of total GDP, with informal employment being far higher [16].

The culture cycle or creative cycle normally consists of creationproduction-dissemination-exhibition/transmission.

- Creation: The originating of ideas and content and the making of the crafts

- Production: The required tools, infrastructure and processes for their realization 


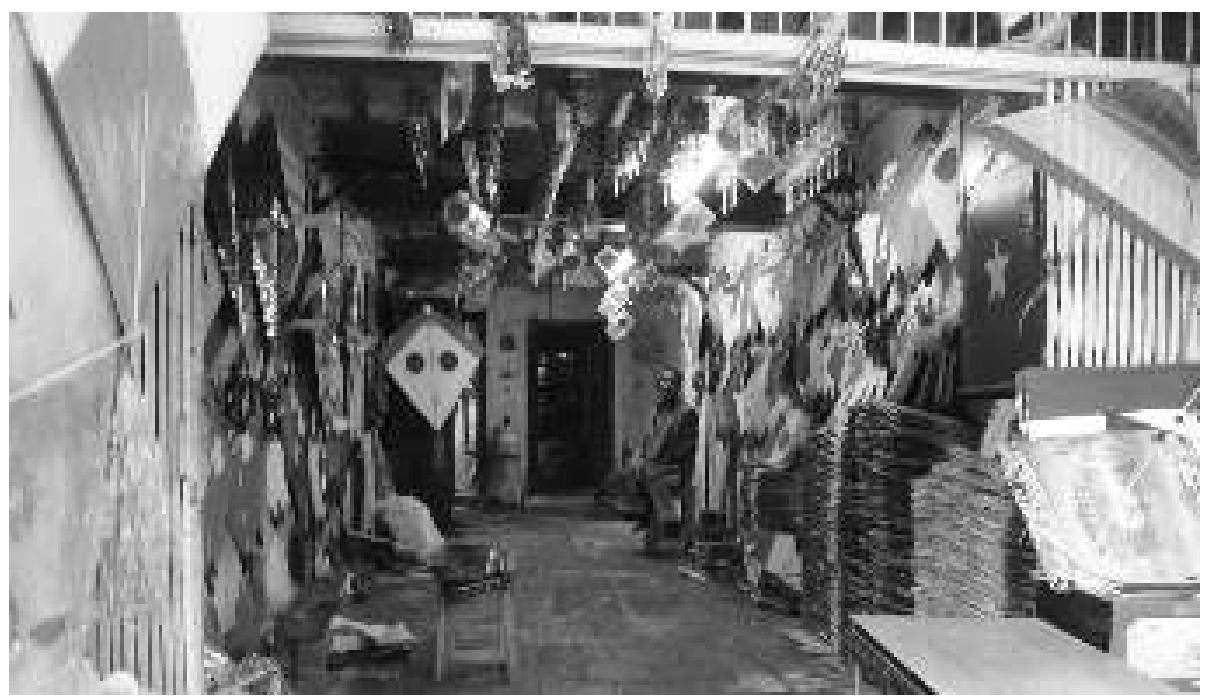

Regenerating Historic Urban Areas Through

Sustainable

Livelihoods -

Problematizing Economy Within

Historic Urban

Areas

Figure 7: Kite making - The space includes creation and sale areas.

- Dissemination: The chain of products reaching out to the consumers, exhibitors, etc.

- Exhibition/Reception/Transmission: This stage mainly refers to the place of consumption and experiences of the cultural activities by the community. Transmission also relates to the transfer of knowledge and skills from generation to generation [13].

Considering that crafts production is idiosyncratic and region based, detailed study with empirical data would be needed for a comprehensive understanding of the system.

\section{TRANSFORMATIONS IN THE INDIAN HISTORIC AREAS}

Though traditional craft skills have historically been a regular means of earning livelihood in India, at present they suffer from declining skills, lack of markets, devaluation of hand-crafted products and, lack of sustainable livelihood opportunities in the modern world. Especially in the urban areas, they are almost on the way to vanishing. Two main challenges are observed with regard to the traditional crafts:

i These crafts are disappearing at a fast pace in the urban areas, thereby contributing to the loss of identity

ii. Traditional craftsmen are facing the issue of growing unemployment. 
Jigyasu, N

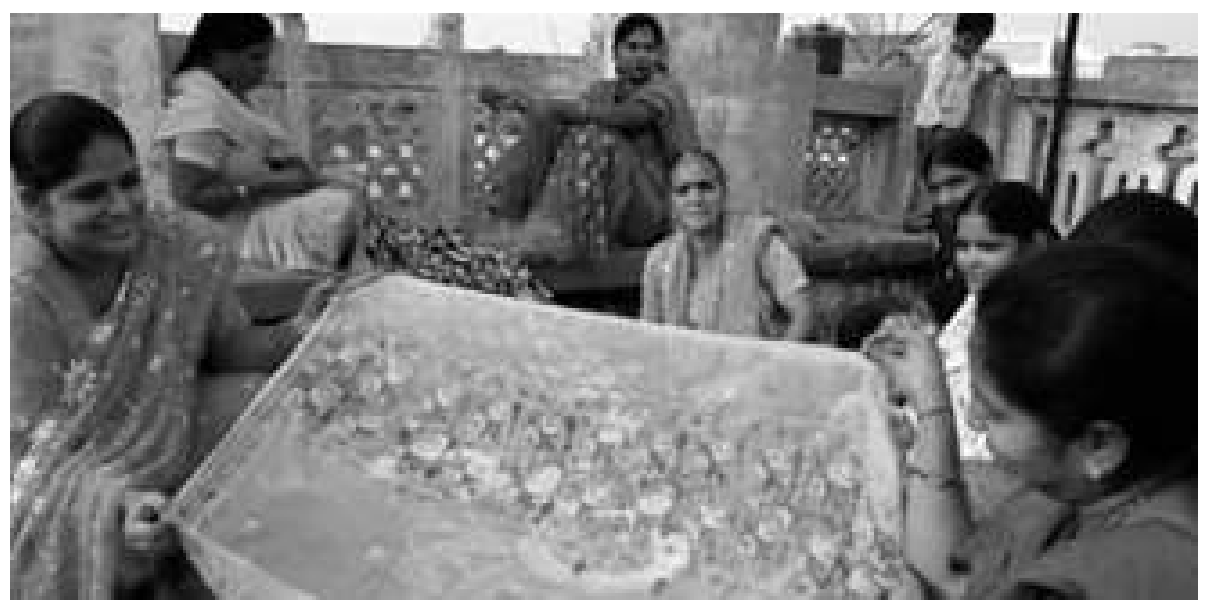

Figure 8: Phulkari making - a social and economic activity, now pushed to villages.

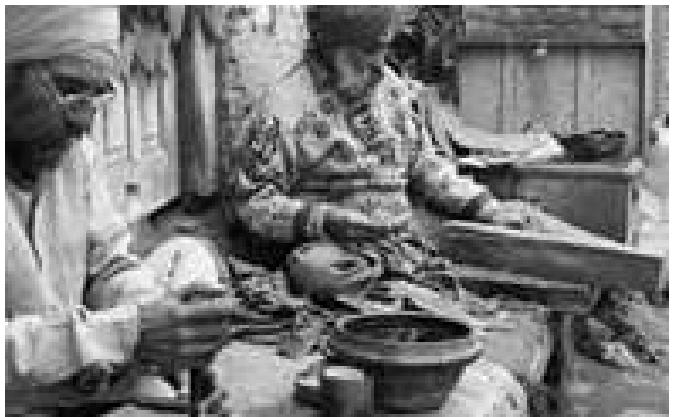

Figure10: Use of technology for sourcing designs and making farma (cover).

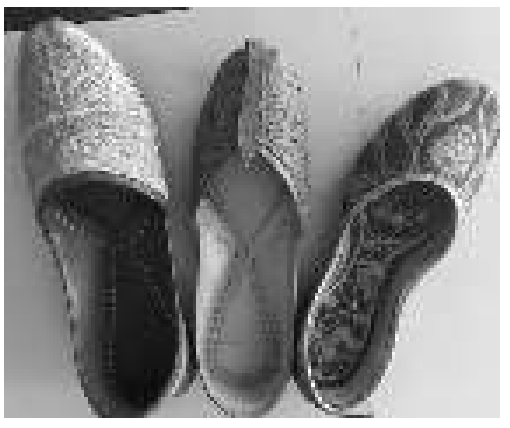

Figure 9: Jutties - absence of elaborate hand-sewn work.

A brief study of Patiala, a historic town in Punjab, brought forth certain revelations. Patiala is a historic town from 1963 constructed by militiamen Sardar Lakhna and Baba Ala Singh with its fair share of heritage structures including the Qila Mubarak. It is also home to traditional crafts like Phulkari (embroidery work), nadda (tie strings), jutti (footwear) and parandah (hair accessory), brief description of which is given below:

Phulkari: It is a style of embroidery that is also seen in other parts of Panjab. The study in Patiala shows that it is now mostly outsourced to the villages around the city (Fig. 8). The artisans (who had learnt the craft from their parents) when interviewed revealed that their present involvment in the craft is only as shopkeeper. Also, there is a competition from the machine-made work from Ludhiana and similar work brought from artisans in Kolkata. The import 

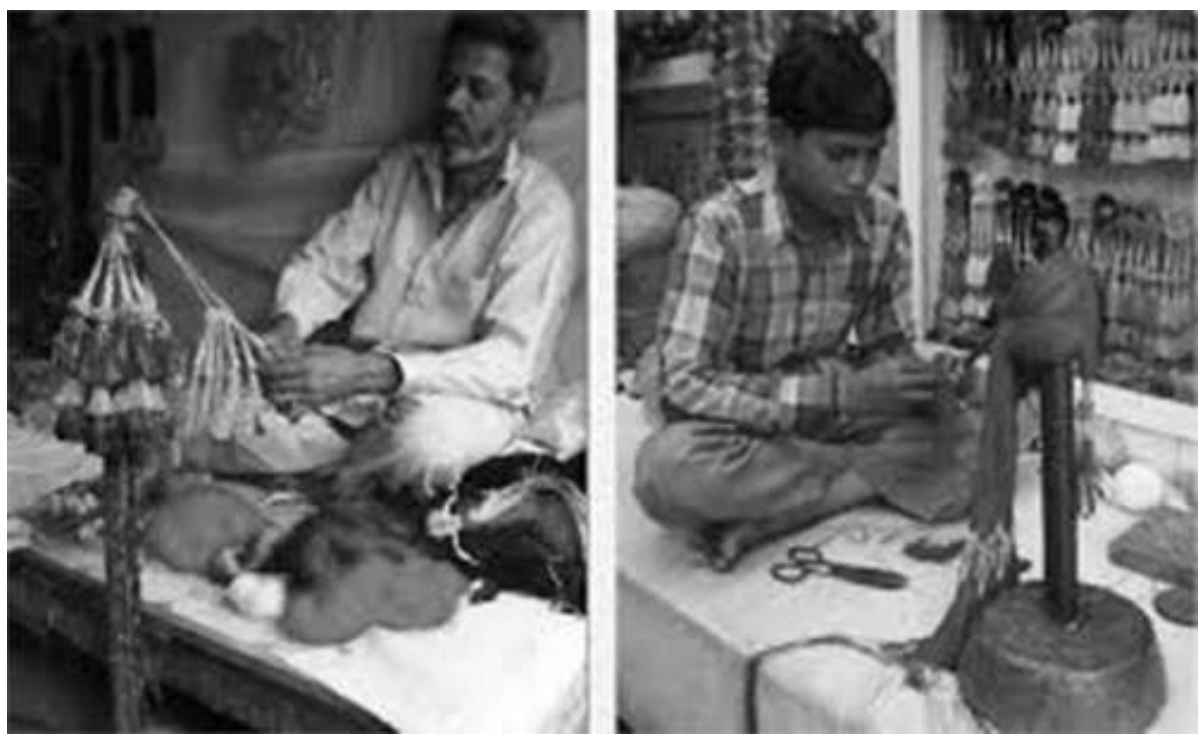

Regenerating Historic Urban

Areas Through

Sustainable

Livelihoods -

Problematizing

Economy Within

Historic Urban

Areas

Figure 11: Parandahs - Continued use of original hand-crafted techniques.

gives a wider selection range for the customer but, due to its lower price, offers a stiff competition to the authentic work.

Jutti: It was interesting to note that the artisans practicing this craft had originally come from Rajasthan some 70-80 years earlier. They were originally into the business of making horse saddles, covers for swords, etc., but with the end of royalty, the demand for such articles started diminishing and they shifted to making juttis. Today, they too have become shop owners, leaving the juttimaking to a labour force that are not traditionally-trained artisans but who have learnt this skill in recent times for their livelihoods (Fig. 9). Also now with most of the work being done by machines, the authentic hand-crafted jutti is not to be seen except in some remote places of Panjab like Nabha, from where it is sourced to Patiala. In addition, computer and information technology is being used for designing, mass production as well as understanding the latest market trends (Fig. 10). Today, the market also includes sourcing juttis from other places within and outside Panjab, including Pakistan, while they are also exported to places like Dubai and Muscat.

Parandahs: As narrated by an artisan, considering the low margins, only 20 families remain in this business within the Patiala city. This craft involves the entire family including women and children (Fig. 11). Also, they need to keep track of the latest interest of the people and, hence, have to keep abreast with 


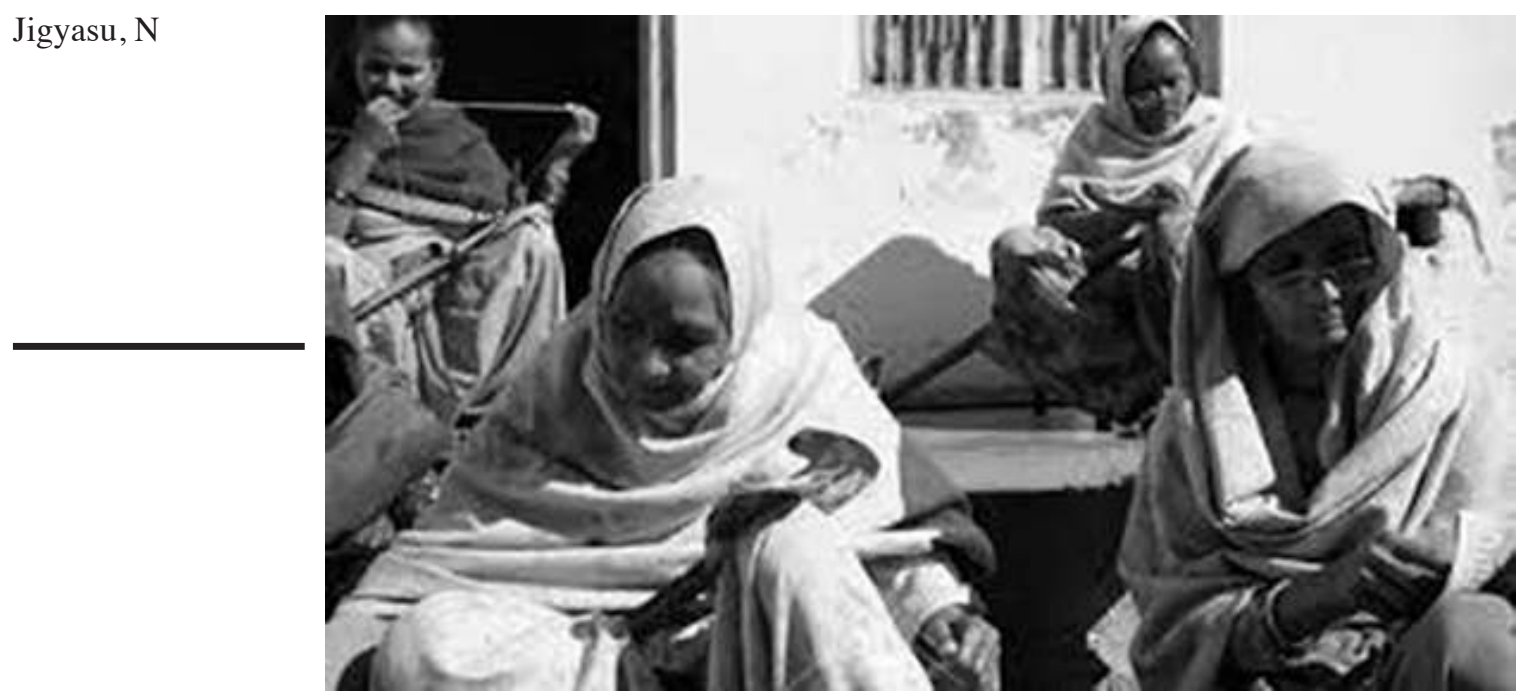

Figure 12: Women are totally absent from today's artisanal setting.

various available accessories that can be used to make the product. Though the basic form remains, the latest options have been heavily contemporized to meet today's fashion. It was refreshing to know that parandahs are still made with completely manual techniques and no machine is used for their production. On the other hand, this also leads to low production and, hence, low income.

The major issues and opportunities that came to the fore through this study include:

i. Loss of interest in crafts among the younger generation owing to low revenue generation.

ii. Competition from present technology, which considerably reduces the manual labour and help in faster mass production. For example, computer generated designs and machine made juttis are cheaper and sell more.

iii. Adaptation of crafts to contemporary demands without losing their essence is needed.

iv. Traditional social systems are breaking up and the younger generation wants to move out of historic urban areas.

v. Women are leaving traditional craft-based occupations. Due to low income generation, lack of hand work and with change of lifestyle, women - especially those working in the jutti craft have left the profession (Fig. 12). 
vi. Far more competitive options are available for the customers. For example, besides traditional Patiala craft of Phulkari, a similar one from Kolkata is also available for customers. Similarly besides local juttis, the same from Pakistan, Malud and Nabha are also available in Patiala.

vii. Some crafts, like the Patiala Nada, have almost disappeared since there is not enough demand in the market.

\section{CONCLUSION}

The scope of urban conservation should not only be limited to historic buildings, but should also be sensitive to the social dimension implicit in the traditional practices, including local crafts. Conservation and development must be approached in a more complex and multidisciplinary way that will embrace planning and management to resolve the competing goals of conserving heritage values while integrating with inclusive social and economic development. Many non-governmental and public organizations as also private institutions are working in the field for craft revitalization, but their work is generally focused on a single craft, sometimes totally independent of the context of the place. However, it is important to address crafts as a component of local economy within the historic urban area and not as a single independent entity. Bringing linkages of economic component to traditional crafts to the fore is very critical to developing a new paradigm for urban regeneration and revitalization of heritage towns and cities. This will facilitate a robust economy founded on jobs that contributes towards local values and pride. This will have longer term impact on improving the quality of life of the inhabitants, which will also help in protecting the built heritage.

\section{REFERENCES}

[1] ABAKERLI, S. (2012) Crafting India's Economic Growth and Development, Context, 9 (2), pp. 4-6.

[2] BANDARIN, F. and OERS, R. (eds.) (2015). Reconnecting the City: The Historic Urban Landscape Approach and the Future of Urban Heritage. West Sussex: Wiley

[3] HOSAGRAHAR,J.(2013) Background Note to Session on Culture's Contribution to Achieving Sustainable Cities. In: Proceedings of the International Congress on Culture: Key to Sustainable Development, Hangzhou, 15-17 May 2013. Paris: UNESCO.

[4] INDIAN NATIONAL TRUST FOR ART AND CULTURAL HERITAGE (2015) Urban Heritage in Indian Cities: Compendium of Good Practices. New Delhi: National Institute of Urban Affairs.
Regenerating Historic Urban

Areas Through

Sustainable

Livelihoods -

Problematizing

Economy Within

Historic Urban

Areas 
Jigyasu, $\mathrm{N}$

[5] INTERNATIONAL COUNCIL ON MONUMENTS AND SITES (1987) Charter for the Conservation of Historic Towns and Urban Areas (Washington Charter 1987). Available from https://www.icomos.org/charters/towns_e.pdf [Accessed: 27 February 2016]

[6] MAHURKAR, U. (2013) Monumental neglect, Thwarting efforts to preserve history, residents misuse medieval structures. India Today 26th June. Available from http://indiatoday.intoday.in/story/thwarting-efforts-to-preserve-historyahmedabad-residents-misuse-medieval-structures/1/306074.html [Accessed: 30 May 2016]

[7] MOON, B.K. (2013) Secretary-General's remarks at General Assembly thematic debate on Culture and Sustainable Development. [Online] UN. Available from https://www.un.org/sg/en/content/sg/statement/2013-06-12/secretary-generalsremarks-general-assembly-thematic-debate-culture [Accessed: 27 May 2016]

[8] O'BRIEN, J. (2012) Livable Historic City Cores and Enabling Environment: A Successful Recipe to Attract Investment to Cities. In: LICCIARDI, G. and AMIRTAHMASEBI, R. (eds.) The Economics of Uniqueness: Investing in Historic Cores and Cultural Heritage Assets for Sustainable Development, 1st ed. Washington DC: World Bank,pp. 1-14.

[9] PIPLANI, N. (2012) Challenges and Potentials for World Heritage Involving Communities Case Study: Taj Mahal, India. In: Proceedings of the International Conference on Involving Communities in World Heritage Conservation Concepts and Actions in Asia,Buyeo, 10-12 September 2012. Paris: UNESCO, pp. 99-109.

[10] SANTAGATA, W. (2004) Cultural Districts and Economic Development. EBLA Working Papers, 01/2004, Torino: University of Turin

[11] TAYLOR, K. (2013) Cultural Mapping: Intangible Values and Engaging with Communities with Some Reference to Asia, The Historic Environment, 4 (1), pp. $50-61$

[12] THROSBY, D. (2010) The Economics of Cultural Policy. New York: Cambridge University Press

[13] UNESCO INSTITUTE FOR STATISTICS (2009) The 2009 UNESCO Framework for Cultural Statistics. Montreal: UIS.

[14] UN-HABITAT (2015) Habitat III Issue Papers - 4: Urban Culture and Heritage. Available from http://www.unesco.org/fileadmin/MULTIMEDIA/HQ/CLT/pdf/ISSUE-PaperEn.pdf [Accessed: 17 January 2016]

[15] UNITED NATIONS EDUCATIONAL, SCIENTIFIC AND CULTURAL ORGANIZATION (2008) Historic Districts for All: A Social and Human Approach for Sustainable Revitalization. UNESCO Working Document, 09/2008, Paris: UNESCO 
[16] UNITED NATIONS EDUCATIONAL, SCIENTIFIC AND CULTURAL ORGANIZATION and UNITED NATIONS DEVELOPMENT PROGRAMME (2013) Creative Economy Report 2013 Special Edition: Widening Local Development Pathways. New York: UNDP

[17] YANG, M. (2015) Culture in Moving the MDGs to the Post-2015 Development Agenda: Some Reflections on the Role of Living Heritage for Sustainable Development. In: ALBERT, M. (ed.) Perceptions of Sustainability in Heritage Studies - Volume 4 of Heritage Studies. 1st ed. Berlin:Walter De Gruyter, pp. 21-34.
Regenerating Historic Urban Areas Through Sustainable Livelihoods Problematizing Economy Within Historic Urban Areas 